\title{
AUTOMATION AND URBAN TRANSPORT PLANNING: POLICY RECOMMENDATIONS AND BEST PRACTICES
}

\author{
ALBERTO DIANIN \& FEDERICO CAVALLARO \\ Institute for Regional Development, Eurac Research, Italy
}

\begin{abstract}
Although Automation is expected to play a crucial role in the future development of transport, currently it lacks strong relations with urban mobility planning. Most types of plans such as SUMPs do not include operative references to Automation, overlooking strategic guidelines or useful measures to integrate this theme into the future vision of mobility. Such a lack represents a missed opportunity, since Automation could stimulate a more collective-oriented mobility paradigm and reduce most of the negative externalities generated by transport. The aim of this contribution is to highlight the importance for transport planning to start dealing with this process in a more rigorous way. For this purpose, the potential effects that Automation may have on transport and land use are summarized in three main types of scenarios. Then, a series of goals are identified, policy recommendations are provided, and exemplificative best practices as well as virtuous urban mobility plans are described.

Keywords: automation, SUMP, land use, transport behaviour, transport systems.
\end{abstract}

\section{INTRODUCTION}

Even if empirical evidence is still missing, Automation is expected to stimulate a crucial transformation in our lifestyles [1], especially referring to transport systems, travel behaviours, and land uses. The results of this process are complex to foresee [2] because of uncertainties related to technical and organizational issues (e.g. concerning legal constraints, automation levels, and communication systems) and the different policy-driven measures applicable to this technology. Indeed, automated vehicles (AVs) may either encourage a more collective and shared mobility paradigm, or increase the appeal of individual and car-dependent mobility, according to the supporting measures. Both end users and public authorities (PAs) can play a core role in these alternative developments. Policy-makers in particular are considered crucial for the promotion of a sustainable vision of Automation, since they can integrate automated-related measures in transport plans and thus foster a new vision of public transport (PT) that takes into account this innovation [3], [4].

Nevertheless, most of the current sustainable urban mobility plans (SUMPs) (i.e. the typical tools that policy makers can adopt to address current and future mobility issues) do not provide guidelines for an active integration of AVs into a collective transport system [5], limiting themselves to considering the regulations needed to allow trials on public streets. Such plans are adopted by numerous urban areas to guide the development of urban transport on medium/long-term ranges, but they barely include any significant policy implications about Automation. As a result of this lack, some recent studies have been developed to upgrade the original SUMP Guidelines written in 2013 (e.g. the Practitioner Briefing for Road Vehicle Automation in Sustainable Urban Mobility Planning [6]) and have brought this topic to greater attention. This article wants to contribute to this research line, highlighting the importance of integrating AVs into transport planning and providing some initial recommendations.

The article is structured as follows: Section 2 introduces the relation between SUMPs and AVs. Section 3 summarizes the main effects that Automation may produce. Based on highlighted challenges, Section 4 proposes policy recommendations that SUMPs should take into account; while Section 5 displays sample best practices and virtuous plans already trying 
to take into account Automation. Finally, Conclusions gives potential research insights into the relationship between Automation-transport planning.

\section{URBAN MOBILITY PLANS AND AUTOMATION}

According to the concept and guidelines developed by the European Commission [7], SUMPs generally aim to revise classic planning processes by proposing a more integrated approach. A SUMP focuses on the improvement of the accessibility and quality of life, sustainability and environmental quality, economic viability and social equity. To meet these targets, SUMPs "foster the balanced development of all relevant transport modes while encouraging a shift toward more sustainable modes" [7]. Despite such focus and their innovative approach, most of the current SUMPs do not include Automation-related strategies [1], referring only to their legal challenges or to possible cooperation with digitalization processes [8].

Nevertheless, SUMPs could represent a valuable tool to build strategies related to Automation and set the ground for future visions of mobility [5], [9]. Indeed, various features typical of SUMPs [7] can deal with the different implications of AVs:

- SUMPs work on medium- and long-term ranges (such as 15 or 20 years) for long-lasting planning. On this time framework, Automation is expected to unlock several potentials, since SAE4 and SAE5-level AVs (i.e. vehicles able to perform all driving tasks autonomously) could be reached [1]. Therefore, a long-term planning prospective is of great importance for Automation.

- SUMPs are often based on the integration of complementary fields concerning, for example, urban, environmental, and ITS planning. Such a multidisciplinary approach may be crucial also in tackling Automation, since AVs involve different domains (legislation, communication systems, and digitalization processes [10]) and impact transport, land use, and social inclusion [11].

- To achieve a better balance among transport modes, SUMPs usually attempt to enhance the multimodal coordination among means, the diffusion of non-motorized options, and the quality of first/last-mile links. Also for these purposes, AVs may offer valuable support (see Section 3) if the planning strategies lead their potentials towards a collective transport vision.

- Finally, SUMPs deal with scenarios to understand the potential long-term effects of alternative measures. Many academic studies about AVs have shown how different interpretations of AVs might lead to different results. Such references may strongly support the inclusion of Automation in policy-oriented tools such as SUMPs.

According to these points, higher attention paid by these transport plans to the challenges concerning Automation could be very promising for their optimal integration into future transport networks.

\section{THE EFFECTS OF AUTOMATION ON TRANSPORT AND LAND USE}

In contrast to policy-related documents, which deal partially with Automation (see the previous section), academic research has been increasing its focus on this topic [2]. In particular, many provisional studies have been developed in the last five years, with the scope to shed light on the potential effects of Automation on transport and land use [12]-[15]. These studies may suggest possible ways to integrate AVs into transport planning, since they show how different interpretations, ways of adoption, and measures could lead to alternative results. To forecast such results (usually concerning variation in modal split, road traffic, congestion, and household location), studies employ provisional models (as agent-based or 
land use/transport interaction models), and feed them inputs based on given assumptions. These inputs concern a series of themes relevantly affected by AVs, such as the road capacity, the road safety, the travel time costs, the operational costs, and the ownership of vehicles.

According to Soteropoulos et al. [2], Stead and Vaddadi [11] and Milakis et al. [16], three main types of scenarios describing alternative results can be identified (S1, S2, S3). The following list explains them in detail, while Table 1 provides a visual summary of their inputs and results.

Table 1: Summary of the three types of scenarios related to Automation and transport.

\begin{tabular}{|l|l|l|l|l|}
\hline & & S1 & S2 & S3 \\
\hline Themes & & Inputs & Inputs & Inputs \\
\hline Road capacity & $\Rightarrow$ & Increased & Increased & Increased \\
\hline Road safety & $\Rightarrow$ & Increased & Increased & Increased \\
\hline Travel time costs & $\Rightarrow$ & Decreased & Decreased & Decreased \\
\hline Operational costs & $\Rightarrow$ & Maintained & Very decreased & Decreased \\
\hline $\begin{array}{l}\text { Parking } \\
\text { time/monetary costs }\end{array}$ & $\Rightarrow$ & Decreased & Decreased & Decreased \\
\hline User inclusiveness & $\Rightarrow$ & Increased & Very increased & Very increased \\
\hline Ownership model & $\Rightarrow$ & Mainly individual & Mainly shared & Mainly rideshared \\
\hline Vehicular fleet & $\Rightarrow$ & Maintained & Decreased & Very decreased \\
\hline AV/PT cooperation & $\Rightarrow$ & Not established & Not established & Established \\
\hline $\begin{array}{l}\text { Need for } \\
\text { parking/road space }\end{array}$ & $\Rightarrow$ & Maintained & Decreased & Decreased \\
\hline & $\Rightarrow$ & $\Re$ & $\Re$ & \} $\\
{\hline \text { Themes }} &{\Rightarrow} &{\text { Mainly to suburbs }} &{\text { Partially to suburbs }} &{\begin{array}{l}\text { Partially to urban } \\
\text { cores }\end{array}} \\
{\hline \text { Modal shift }} &{\Rightarrow} &{\begin{array}{l}\text { from PT and slow } \\
\text { mobility to AVs }\end{array}} &{\begin{array}{l}\text { from PT and slow } \\
\text { mobility to shared } \\
\text { AVs }\end{array}} &{\begin{array}{l}\text { From private means } \\
\text { to rideshared AVs } \\
\text { and PT }\end{array}} \\
{\hline \begin{array}{l}\text { Road traffic (in } \\
\text { VMT) }\end{array}} &{\Rightarrow} &{\text { Very increased }} &{\text { Increased }} &{\text { Decreased }} \\
{\hline \begin{array}{l}\text { Congestion } \\
\text { relocation }\end{array}} &{\Rightarrow} &{\text { Increased }} &{\text { Partially increased }} &{\text { Decreased }} \\
{\hline}$
\end{tabular}

S1. The first type of scenario assumes that AVs replace cars and are subject to the same ownership model of nowadays, i.e. they are mainly owned by individuals, while sharing services remain ancillary. No particular cooperation exists between AVs and PT, similarly to what currently happens with cars. Even the overall vehicular fleet remains almost unvaried, since sharing is a minor practice. Besides, AVs are presumed to provide road transport users with several performance-related benefits such as: a strong increase of road capacity and safety thanks to their ability to work in platoon; a reduction in the travel time costs thanks to the possibility of passengers 
performing useful activities while travelling; a decrease of the parking-related times and monetary costs, since users can be dropped-off and picked-up by AVs in the most convenient manner. At the same time, AVs maintain operational costs very similar to current cars, since they are individually owned and thus incur similar costs. Insurance should be lower, since the risk of crashes is highly reduced. Self-driving skills also allow entrance of new types of users into the market, such as disabled people, the elderly, and children. Finally, the current need for parking facilities remains almost identical even if such spaces could be partially relocated, while roads can be resized a little thanks to the improved road capacity performances. Based on these inputs, scenarios reveal a modal shift of PT and slow mobility users to AVs, due to the several benefits provided by this innovation. This shift, together with cited inputs such as the addition of new users and the performing of empty runs due to a different management of parking practices, feed a strong increase of road transport in terms of vehicle miles travelled (VMT), with negative effects in terms of congestion. Furthermore, urban sprawl increases, according to the diffused household relocation in more distant and cheaper suburbs. This phenomenon is backed by the benefits concerning road capacity and travel time costs, which encourage people to travel longer commuting distances.

S2. The second type of scenario assumes that AVs replace cars and are mostly used both as shared and ride-shared vehicles, while ownership of vehicles decreases sharply. This assumption is supported by other related inputs. First, the vehicular fleet diminishes consistently, with estimated drops of up to $80 \%$ [17] thanks to the continuous operation of shared AVs. Second, the operational costs fall significantly due to the abandoning of ownership. Third, the need for parking facilities and road spaces decreases consistently, as a result of fleet reduction. In this framework, shared AVs are not organized in cooperation with PT and slow mobility, offering rather an alternative option. With regards to the other performance-related benefits, similar inputs to those applied in S1 are included, i.e. an improvement of road capacity and safety, reduction in travel time costs, and reduction in parking-related times and monetary costs, also because pick-up and drop-off operations become the most usual practices. Finally, even in this scenario AVs allow the entrance of new users into the market, including low-income people benefiting from the reduced operational costs. Based on these inputs, scenarios reveal a strong modal shift of PT and slow mobility users to AVs, due to the several benefits given by this alternative (especially for operational costs). According to this shift and the entrance of new users into the market, the VMT are presumed to increase, even if this growth is limited by a reduced vehicular fleet. The related effects on congestion are variable: during peak hours the strong use of AVs may affect main corridors, during the rest of the day the sharing model makes the traffic smoother. In addition, urban sprawl increases, due to the reasons listed in S1 and the assumption of lower operational costs. However, urban areas also gain appeal and new households, since sharing models are more efficient in dense areas.

S3. The third type of scenario assumes that AVs replace traditional cars and are mostly used for ridesharing services, while the ownership of vehicles is almost abandoned. Consistent with this input, the overall vehicular fleet decreases like in S2 but to a greater extent, since ridesharing is the predominant model. The need for parking facilities and road spaces decreases according to the reduced fleet. In combination with these inputs, AVs are presumed to be organized in cooperation with PT (especially with high-capacity services). Thus, AVs act mainly as feeders for PT, by solving first/last-mile issues, covering peak-offs, and improving multimodal 
connections. As in S2, also in this case operational costs decrease due to ridesharing, even if to a minor extent. As for the performance-related inputs, they are similar to those cited in previous scenarios: road safety and capacity increase, the travel time costs are reduced, the parking-related times and monetary costs are significantly decreased thanks to the high diffusion of ridesharing. Finally, the availability of AVs also for new types of users is introduced. Based on these inputs, a partial growth of PT users is expected, thanks to the support provided by AVs in making the whole collective transport system more efficient. According to this condition and the diffusion of ride-shared AVs, the overall VMT decreases. At the same time congestion diminishes, thanks to the benefits deriving from the combination of AVs and high-capacity means in peak hours. Urban sprawl is limited as well, since an integrated PT/AV system makes urban areas more appealing and long distances by AVs less attractive.

$\mathrm{S} 1$ and S2 scenarios are included in several provisional studies, in order to highlight how much sharing may radically change the effects of Automation. In contrast, a S3 scenario is proposed only by some studies, since it implies more complex relations among the involved parts and also a strong commitment of public authorities in revising the whole PT system.

In this light, AVs may produce very heterogeneous and even opposite effects on transport systems, behaviours, and land uses, depending on the hypothesized inputs. On the one hand, AVs may emphasize the current dependency on individual transport to the detriment of PT and slow mobility, as well as stimulate the growth of suburban and sprawling areas (e.g. Meyer et al. [12]), [14]. On the other hand, they may support an increase of collective and shared mobility and promote more compact and mixed settlement structures (e.g. Gelauff et al. [15]). Ultimately, one of the main drivers able to influence the results is the commitment of public authorities and policy makers, who are called to address this innovation actively by promoting related measures and planning strategies able to foster a more collective-oriented mobility paradigm [3], [4].

\section{POLICY RECOMMENDATIONS}

Based on the necessity to integrate Automation into strategic transport plans, this section provides sample policy recommendations that PAs may take into account. These recommendations are organized into five clusters, each representing a goal to pursue in order to make Automation part of a collective-oriented transport system. The five goals are selected according to the main inputs included in S3 and highlighted in studies dealing with this type of scenario (e.g. Duarte and Ratti [18], Papa and Ferreira [19] and Hensher [20]). These goals are: 1) Shifting users from owning to sharing vehicles; 2) Promoting the cooperation of AVs and PT; 3) Converting recovered parking and road spaces; 4) Reorganizing stopping/parking practices; 5) Applying Automation to different means.

\subsection{Policy recommendations for shifting users from owning to sharing vehicles}

To promote a sharing-based model of transport, the development of a competitive fleet of rideshared AVs is a fundamental prerequisite. PAs should deal with, for example, the setup of new traffic management units and technical departments able to manage traffic tasks and control the information flows among connected AVs [9]. This is necessary to allow the smooth inclusion of different operators within a unique publicly run system. In parallel, operational costs for these services should be appealing, while individual travel should be discouraged. For example, on-demand ridesharing incentives and special charges related to the occupancy rate and the performing of empty runs could be introduced [21]; also the 
marginal costs of ridesharing should impact the cost perception of users as little as possible [14]. In order to make AV fleets smooth, PAs have to harmonize them across administrative borders and among areas with different urban density to reach a seamless condition. Moreover, the promotion of shared mobility can already be carried out, to get people used to alternative concepts of mobility [4].

\subsection{Policy recommendations for promoting the cooperation of AVs and PT}

To achieve cooperation rather than competition between AVs and PT, PAs first have to promote business models where rideshared AVs feed PT or replace it for particular demand needs. For instance, some automated services can connect high-capacity PT nodes to each other (offering frequent and widespread connections), while others can cover off-peak intervals where conventional PT is lacking [22]. Such kinds of options can be supported with subsidies related to PT integration, to make them more attractive compared to rideshared AVs offering free routes [15], [21]. In this respect, new road pricing policies providing distance/time-related prices can be introduced [20]. The charges are related to the distance covered and the period of the day travelled, discouraging the use of low-capacity means in peak hours and for long journeys. On the other hand, multimodal chains based on high-capacity services are supported. Integrated informative and tariff systems can also be considered, in order to offer a smooth integration among different means and providers.

\subsection{Policy recommendations for converting recovered parking and road spaces}

PAs should also promote measures to convert the spaces recovered by rideshared AVs into new uses capable of supporting sustainable transport behaviours and urban structures. For instance, off-street parking spaces may be reused to increase the functional diversification of involved areas [18]. New commercial activities, recreational areas, residential infills, and service hubs (such as logistic centres) may be placed in such areas, decreasing the need for motorized transport. In parallel, on-street parking spaces and excess road infrastructure may be used to make more road space available for high-capacity PT corridors, as well as for walking and cycling infrastructure [21]. This could make slow mobility and PT links more appealing and their use more diffused. To back these options, regulatory instruments such as compact and mixed-use urban plans may be introduced, as well as regulations limiting the use of green areas for new expansions while subsidising the reuse of recovered spaces for this purpose [11].

\subsection{Policy recommendations for reorganizing stopping/parking practices}

Since Automation skills and rideshared models will radically change parking practices, PAs have to accurately plan how new needs (e.g. for pick-up and drop-off operations) should be managed [11]. PAs can exploit the cooperative approach of AVs to assign available parking lots in the most convenient manner [19], as well as to plan less space-consuming parking areas, based on the removed need to access the vehicles [10]. Furthermore, PAs should implement plans for the management of pick-up and drop-off operations, since these are likely to require relevant spaces, especially in proximity to main destinations and PT nodes and during peak hours, as well as potentially interfere with traffic flows along main corridors [11]. Also, parking schemes and fares across different areas of the city should be subject to strong planning revisions, in order to influence the spatial and temporal distribution of demand and prevent empty runs due to parking reasons. 


\subsection{Policy recommendations for applying Automation to different means}

Finally, PAs should consider that automated technologies may provide benefits to transport means other than cars, and that the design of traditional cars might be obsolete in a transport system based on sharing [18]. For instance, several automated shuttles already on the market fit 15 passengers in $130 \%$ of the surface occupied by a traditional car. The same is valid for single-seat pods, which could save space and provide more tailored services [18]. In addition, Automation may improve high-capacity services, making them more competitive and affordable. Such benefits could in turn make this type of service more diffused compared to nowadays [23]. All five clusters discussed here are shown in Table 2.

Table 2: Policy recommendations for the integration of AVs into urban transport planning.

\begin{tabular}{|c|c|}
\hline Main & Related policy recommendations \\
\hline $\begin{array}{l}\text { Shifting users } \\
\text { from owning } \\
\text { to sharing } \\
\text { vehicles }\end{array}$ & $\begin{array}{l}\text { - Setting up a traffic management unit to manage a fleet of rideshared AVs } \\
\text { - Setting up a technical department to control information flows } \\
\text { among AVs } \\
\text {-Developing on-demand ride sharing incentives } \\
\text {-Developing fees inversely proportional to the occupancy rate } \\
\text {-Dealing with the users' perception of marginal operative costs } \\
\text {-Developing seamless rideshare systems across different territories } \\
\text {-Promoting shared forms of mobility in advance }\end{array}$ \\
\hline $\begin{array}{l}\text { Promoting the } \\
\text { cooperation } \\
\text { of AVs and PT }\end{array}$ & $\begin{array}{l}\text {-Setting up business models for AVs feeding/connecting PT } \\
\text { nodes/services } \\
\text {-Setting up business models for AVs replacing PT during off-peak hours } \\
\text {-Developing subsidies for PT-oriented AV business models } \\
\text {-Developing distance/time-related road pricing schemes } \\
\text {-Developing integrated informative and tariff services }\end{array}$ \\
\hline $\begin{array}{l}\text { Converting } \\
\text { the recovered } \\
\text { parking and } \\
\text { road spaces }\end{array}$ & $\begin{array}{l}\text {-Planning the reuse of recovered spaces to increase functional } \\
\text { diversification } \\
\text {-Planning the reuse of recovered spaces to enforce PT and slow mobility } \\
\text { infrastructures } \\
\text {-Developing compact and mixed-use oriented urban plans } \\
\text {-Developing regulations to limit the use of green areas in favour of } \\
\text { recovered ones }\end{array}$ \\
\hline $\begin{array}{l}\text { Reorganizing } \\
\text { stopping } \\
\text { /parking } \\
\text { practices }\end{array}$ & $\begin{array}{l}\text {-Exploiting the cooperative approach of connected AVs to assign spaces } \\
\text {-Planning less space-demanding parking facilities and areas } \\
\text {-Planning pick-up and drop-off spaces according to main nodes and } \\
\text { traffic flows } \\
\text {-Planning revised parking schemes also according to empty runs }\end{array}$ \\
\hline $\begin{array}{l}\text { Applying } \\
\text { Automation to } \\
\text { different } \\
\text { means }\end{array}$ & $\begin{array}{l}\text { - Considering the revision of low-capacity vehicle design (such as shuttles } \\
\text { or pods) } \\
\text {-Considering the benefits of the adoption of Automation for } \\
\text { high-capacity PT }\end{array}$ \\
\hline
\end{tabular}




\section{BEST PRACTICES}

Different best practices in Europe, America, and Asia already address some of the themes about Automation presented above. This section provides some examples concerning both on-field policies (Subsection 4.1) and virtuous mobility plans (Subsection 4.2). The selected on-field policies tackle respectively: the development of solutions for cooperation between AVs and PT; the application of automated technologies to means alternative to cars; and the conversion of parking spaces into new uses for urban life. The selected virtuous mobility plans refer to cities of three different continents (Singapore, London, and Seattle) and are either integrations to SUMPs or complementary strategic plans.

\subsection{Sample on-field policies}

The Transdev mobility company provides a good example of integration between different mobility solutions that aim for cooperation between AVs and PT [22] (see Table 3). Specifically, it experiments in test areas with various combinations of usual PT services and demand-responsive rideshared AVs. In Rouen, for example, AVs connect a residential area with the main PT nodes available in its surroundings. For this purpose, three circuits of $10.5 \mathrm{~km}$ serving 17 stops with a fleet of e-cars supported by an App for customers are arranged. In Paris-Saclay, AVs provide PT services during the night and off-peak hours, connecting main stations and neighbourhoods by AVs. In Verdun, AVs facilitate the mobility within city centres and tourist areas. This solution aims to serve users with limited mobility or knowledge of the location, in order to access both the main attractions of the city and the main PT and park-and-ride hubs. Finally, in Rungis AVs provide transport services within private areas with limited or forbidden access to cars. This kind of option may be suitable for hospitals, campuses, big companies, or airports, making movement for visitors and workers easier.

Regarding alternative applications of automated technologies, the trackless tram introduced in 2017 in Zhuzhou (China) is an interesting example [24] (see Table 3). Since it runs on rubber wheels on ordinary streets by following a GPS high-precision route, it is very similar to a bus. Nevertheless, it possesses numerous positive features of trams while avoiding several negative aspects of buses. First, it can travel at speeds of $70 \mathrm{~km} / \mathrm{h}$ and carry up to 300 passengers with three carriages or 500 with five. Thanks to its train-like layout and automated driving skills, it offers a high ride quality and precision when approaching platforms. However, since it runs on wheels and is powered by electric batteries, it has costs considerably lower than conventional light rail services amounting to about €6-8m per kilometre. Thanks to such benefits, trackless trams can be a valuable solution to bring appealing high-capacity PT options also into suburbs currently served by unappealing bus lines. Their introduction can also attract urban development around stations, preventing further urban sprawl while stimulating agglomeration effects in the involved areas.

Policies for the conversion of parking and road spaces into new uses can provide important land-use benefits in terms of functional diversification. Exemplificative in this sense is the "Pavement to Parks" initiative, which has been spreading in San Francisco since 2010 [25] (see Table 3). This is not specifically focused on Automation, but on highlighting which benefits in terms of urban relations could be generated by converting road parking spaces into different uses oriented towards people and slow mobility. Indeed, this concept is grounded in the necessity to reverse the car-dominant paradigm that has dominated the urban development of San Francisco in the last 50 years, by giving back road space to people. In the last ten years, the initiative has turned about 60 clusters of road-side parking spaces into external spaces for restaurants, services for bikes, green spaces, and recreational areas. These 
conversions have led to positive results for the involved neighbourhoods, providing an increase of people walking or cycling and of the number of customers of the commercial activities along the involved streets. If considered to a greater extent according to a diffusion of rideshared AVs, these transformations could provide more radical benefits, with a relevant increase of appeal for the transformed areas.

Table 3: The Transdev mobility company, the trackless tram of Zhuzhou and the "Pavement to Park" initiative.

\begin{tabular}{|l|l|l|}
\hline $\begin{array}{l}\text { The Transdev mobility } \\
\text { company }\end{array}$ & $\begin{array}{l}\text { The trackless tram of } \\
\text { Zhuzhou }\end{array}$ & $\begin{array}{l}\text { The "Pavement to Park" } \\
\text { initiative }\end{array}$ \\
\hline Main features & Main features & Main features \\
\hline $\begin{array}{c}\text { It proposes combinations } \\
\text { of AVs and PT }\end{array}$ & $\begin{array}{l}\bullet \text { It maintains the main } \\
\text { skills and driving benefits } \\
\text { of trams } \\
\text { AVs are mainly conceived } \\
\text { as feeders of PT }\end{array}$ & $\begin{array}{l}\bullet \text { It tries to reverse the } \\
\text { ongoing car-oriented } \\
\text { paradigm } \\
\text { costs compared to classic } \\
\text { some gaps of classic PT } \\
\text { trams } \\
\text { involved streets }\end{array}$ \\
$\begin{array}{l}\bullet \text { It can improve the supply } \\
\text { of suburbs and affect } \\
\text { land uses }\end{array}$ & $\begin{array}{c}\text { It stimulates slow mobility } \\
\text { and commercial relations }\end{array}$ \\
& & \\
\hline
\end{tabular}

\subsection{Sample of virtuous mobility plans}

A positive example is represented by the Smart Mobility Plan 2030 of Singapore and its subsequent integration with a focus on AVs [26], [27] (see Table 4). The initial plan was first developed in 2013. Initially, it integrated only general references to the use of AVs, while its main focus was on the role of ITSs in providing smoother PT and sharing options. On this basis, in 2017 the Land Transport Authority (LTA) started to include Automation-related aspects more actively. AVs have been interpreted as a sustainable resource to improve PT and tackle the growing population, the related transport demand, and the diversification of transport needs. In this respect, AVs are planned to be used both to provide fixed and scheduled services (such as self-driving buses), and to cover point-to-point on-demand needs. Also, logistics of port and freight hubs are supposed to be improved thanks to a fleet of platooning trucks, while services such as road sweeping and waste hauling should be managed with specific AVs. This vision considers AVs not as a private means but rather as a complementary part of PT.

Even the city of London is increasing its focus around this theme, as confirmed by the report "Future Transport" [28] (see Table 4). This highlights innovative technological challenges the city is expected to face, including Automation. The document stresses that AVs may represent a good opportunity to increase sharing and reduce traffic, however this can happen only if shared services are made a normal way of traveling for Londoners. To spread shared AVs, the report provides several recommendations. For instance, the Car Club strategy should be updated, in order to embed car sharing in the context of Automation; automated bus services should be planned, with particular attention paid to the consequences they may have on the staff of the current bus network; a discussion should be engaged 
between the municipality, the government, and the operators to set core principles for a regulatory regime dealing with new demand-responsive services.

Supported by the University of Washington, the city of Seattle is also actively addressing Automation, by providing recommendations for the main challenges identified within the "Driverless Seattle" report [29] (see Table 4). As for traffic management, three aspects have to be developed: the utilization of AV exchange data to manage traffic patterns more efficiently; the revision of transport planning processes to account for AV features such as on-board benefits; the promotion of AV ownership models supporting traffic efficiency (such as sharing). Regarding the impacts on current revenue and budgeting sources, the report shows that new options should replace current parking revenues, such as VMT related taxes, which should discourage the use of AVs on long distances. Furthermore, other recommendations concern the development of adequate infrastructures for AV introduction, the transformation of insurances, the effects on emergency services, and the consequences on social equity.

Table 4: The Singapore Smart Mobility plan, "Future Transport" for London and "Driverless Seattle".

\begin{tabular}{|c|c|c|}
\hline $\begin{array}{l}\text { Singapore Smart Mobility } \\
\text { plan }\end{array}$ & $\begin{array}{l}\text { "Future Transport" for } \\
\text { London }\end{array}$ & "Driverless Seattle" \\
\hline Main recommendations & Main recommendations & Main recommendations \\
\hline $\begin{array}{l}\text { - Apply AVs to both fixed } \\
\text { and on-demand } \\
\text { passenger services } \\
\text { - Exploit AVs to manage } \\
\text { the logistics in } \\
\text { freight hubs } \\
\text { - Exploit AVs to perform } \\
\text { urban services such as } \\
\text { sweeping and waste } \\
\text { hauling }\end{array}$ & $\begin{array}{l}\text { - Update the Car Club strategy } \\
\text { to unlock sharing AV } \\
\text { services } \\
\text { - Plan automated bus services } \\
\text { and consider the effects on } \\
\text { staff } \\
\text { - Set a regulatory framework } \\
\text { for demand-responsive } \\
\text { services }\end{array}$ & $\begin{array}{l}\text { - Plan new traffic } \\
\text { management systems } \\
\text { - Consider the } \\
\text { transformation of revenues } \\
\text { - Develop adequate } \\
\text { infrastructures for AVs } \\
\text { - Consider the likely } \\
\text { transformations of } \\
\text { insurances } \\
\text { - Plan the development of } \\
\text { adequate emergency } \\
\text { services } \\
\text { - Consider the effects in } \\
\text { terms of social equity }\end{array}$ \\
\hline
\end{tabular}

\section{CONCLUSIONS}

The poor relationship between Automation and transport planning is only slowly changing. Most SUMPs currently include neither strategies for the long-term integration of AVs nor preliminary policy recommendations to tackle their introduction, losing an occasion for the planning of this innovation. As suggested by scientific literature, this lack may be harmful: AVs can either trigger more individual-oriented behaviours or stimulate more shared and collective visions. The degree of commitment of PAs is a crucial driver. For this reason, this article has tried to support a more active involvement in planning, by suggesting a series of goals and related policy recommendations.

However, the complexity of the Automation/transport planning relationship does not only concern the necessity to include policy recommendations in SUMPs, but also other 
behavioural and cultural aspects. For instance, large-scale planning transformations (above the SUMP level) are needed to generate a strong shift in our mobility from an individual to a collective paradigm. Without them, radical changes such as the abandoning of the ownership of vehicles will remain a phenomenon limited to some virtuous contexts. At the same time, such transformations should involve the social sphere. For instance, users of today are used to imagining mobility as an individual practice, according to a vision the narrative of car ownership has been fed over the last 60 years. The users of tomorrow have not yet been born, and their way of thinking about mobility will also be shaped by an image that we are now revising. Besides these broad issues, other challenges affect more small-scale matters, such as the different effects of AVs between urban and rural contexts (which currently face very different trends such as overcrowding and depopulation). All these themes highlight the complexity of this topic, of which there needs to be a better understanding in order to become an occasion to foster a more collective-oriented mobility paradigm.

\section{REFERENCES}

[1] Martínez-Díaz, M. \& Soriguera, F., Autonomous vehicles: Theoretical and practical challenges. Transportation Research Procedia, 33, pp. 275-282, 2018.

[2] Soteropoulos, A., Berger, M. \& Ciari, F., Impacts of automated vehicles on travel behaviour and land use: An international review of modelling studies. Transport Reviews, 39, pp. 29-49, 2019.

[3] Pfaffenbichler, P., Emberger, G., Shepherd, S. \& May, A.D., The Potential Impacts of Automated Cars on Urban Transport: An Exploratory Analysis, 2018.

[4] UITP Advancing Public Transport, Autonomous vehicles: A potential game changer for urban mobility. Policy brief, 2017.

[5] Rupprecht, S., Automation -Ready Urban Mobility Urban Mobility Planning, 2018.

[6] Backhaus, W., Rupprecht, S. \& Franco, D., Road Vehicle Automation in Sustainable Urban Mobility Planning, European Commission Directorate-General for Mobility and Transport Unit B4 - Sustainable \& Intelligent Transport, 2019.

[7] Wefering, F., Rupprecht, S., Bührmann, S. \& Böhler-Baedeker, S., Guidelines. Developing and Implementing a Sustainable Urban Mobility Plan, European Commission Directorate-General for Mobility and Transport Unit C.1 - Clean Transport \& Sustainable Urban Mobility, 2013.

[8] CoEXist, Towards automation-ready SUMPs, 2019. www.h2020-coexist.eu/towardsautomation-ready-sumps/. Accessed on: 19 Jun. 2019.

[9] Rupprecht, S., Backhaus, W., Gyergyay, B. \& Gomari, S., “Automation-ready” Framework, CoEXist project - Horizon 2020, 2018.

[10] Alessandrini, A., Campagna, A., Site, P.D., Filippi, F. \& Persia, L., Automated vehicles and the rethinking of mobility and cities. Transportation Research Procedia, 5, pp. 145-160, 2015.

[11] Stead, D. \& Vaddadi, B., Automated vehicles and how they may affect urban form: A review of recent scenario studies. Cities, 92, pp. 125-133, 2019.

[12] Meyer, J., Becker, H., Bösch, P.M. \& Axhausen, K.W., Autonomous vehicles: The next jump in accessibilities? Research in Transportation Economics, 62, pp. 80-91, 2017.

[13] Viegas, J., Automation and the future of public transport, ITF - International Transport Forum, 2017. www.intelligenttransport.com/transport-articles/72914/automationfuture-public-transport/. Accessed on: 19 Apr. 2019.

[14] Thakur, P., Kinghorn, R. \& Grace, R., Urban form and function in the autonomous era. Australasian Transport Research Forum Proceedings, vol. 15, 2016. 
[15] Gelauff, G., Ossokina, I. \& Teulings, C., Spatial Effects of Automated Driving: Dispersion, Concentration or Both, KIM - Netherlands Institute for Transport Policy Analysis: The Hague, 2017.

[16] Milakis, D., van Arem, B. \& van Wee, B., Policy and society related implications of automated driving: A review of literature and directions for future research. Journal of Intelligent Transportation Systems, 21, pp. 324-348, 2017.

[17] International Transport Forum \& CPB, Urban mobility system upgrade: How shared self-driving cars could change city traffic. Corporate Partnership Board report, 2015.

[18] Duarte, F. \& Ratti, C., The impact of autonomous vehicles on cities: A review. Journal of Urban Technology, 25, pp. 3-18, 2018.

[19] Papa, E. \& Ferreira, A., Sustainable accessibility and the implementation of automated vehicles: Identifying critical decisions. Urban Science, 2, pp. 1-14, 2018.

[20] Hensher, D.A., Tackling road congestion: What might it look like in the future under a collaborative and connected mobility model? Transport Policy, 66, pp. A1-A8, 2018.

[21] Fulton, L., Mason, J. \& Meroux, D., Three Revolutions in Urban Transportation: How to Achieve the Full Potential of Vehicle Electrification, Automation and Shared Mobility in Urban Transportation Systems around the World by 2050, UC Davis Institute of Transportation studies report to the Institute for Transportation and Development policy. Davis (CA): University of California, 2017.

[22] Leriche, Y., Mobility - Shared Autonomous Transport Services, Transdev, vol. 6, 2018.

[23] Newman, P., Why trackless trams are ready to replace light rail. The Conversation, 2018. http://theconversation.com/why-trackless-trams-are-ready-to-replace-light-rail103690. Accessed on: 22 Mar. 2019.

[24] Newman, P. et al., The trackless tram: Is it the transit and city shaping catalyst we have been waiting for? Journal of Transportation Technologies, 9, pp. 31-55, 2019.

[25] Francis, J.M., San Francisco Parklet Manual - Version 3.0, Ground Play and City of San Francisco, 2018.

[26] LTA - Land Transport Authority, Self-driving vehicle initiatives in Singapore, 2017.

[27] Land Transport Authority and Intelligent Transport Society Singapore, Smart Mobility 2030 - ITS Strategic Plan for Singapore, 2014.

[28] Transport Committee, Future transport - How is London responding to technological innovation? Future Transport report, 2018.

[29] Tech Policy Lab, Driverless Seattle - How cities can plan for automated vehicles. Tech Policy Lab, University of Washington report, 2017. 